\title{
Changes in Crystallinity of Gas-phase Oxidized PAN-based Carbon Fibers
}

\author{
Sang-Min Lee, Seong-Moon Oh, Dong-Su Kang, Jae-Seung Roh \\ Kumoh National Institute of Technology \\ Daehakro 61, Gumi, Gyeongbuk, South Korea \\ dark2088@kumoh.ac.kr, smoh@kumoh.ac.kr; dsk@kumoh.ac.kr, jsroh@kumoh.ac.kr
}

\section{Extended Abstract}

Carbon fibers are being increasingly used in many industries such as leisure, aviation, aerospace, military, and energy due to their outstanding characteristics [1]. Using polyacrylonitrile as a precursor, PAN-based carbon fibers undergo electrospinning, stabilization, and carbonization to become lightweight, high-strength carbon fibers [2, 3]. At high temperatures, carbon fibers experience a deterioration of physical properties, which results in various issues [4]. Recently, extensive research has been performed to overcome such issues, and a fundamental step is to understand and analyze the oxidation reactions of carbon fibers [5,6]. This study conducted gas-phase oxidation of PAN-based carbon fibers at $700^{\circ} \mathrm{C}$ in air to examine changes in crystallinity in relation to oxidation reactions. The raw materials used were Toray's T300 and T700. After removing sizing materials at $400^{\circ} \mathrm{C}$ in a tube furnace, gas-phase oxidation (Air, $0.5 \mathrm{~L} / \mathrm{min}$ ) was carried out at $700^{\circ} \mathrm{C}$ over varying times. An X-ray diffractometer was used to examine the crystallinity of gas-phase oxidized carbon fibers. Based on the XRD spectrum, the peaks were separated to calculate the (002) interplanar distance, La, and Lc. The Lc and (002) interplanar distance increased with burn-off amount, and this is attributed to the small crystallites being oxidized before others. The rate of increase of Lc was higher for T300 than T700, and T3 had a smaller Lc at the start of oxidation. The smaller Lc allowed oxidation to take place more rapidly, thereby contributing to the faster rate of increase of Lc.

\section{References}

[1] H. Wang, Y. Wang, T. Li, S. Wu, L. Xu, "Gradient distribution of radial structure of PAN-based carbon fiber treated by high temperature," Progress in Natural Science: Materials International, vol. 24, no. 31, 2014.

[2] M. K. Seo, S. J. Park, "Manufacturing Method of Carbon Fibers and Their Application Fields," Polymer Science and Technology, vol. 21, no. 130, 2010.

[3] M. K. Seo, K. E. Choi, B. G. Min, S. J. Park, "Carbon Fibers I: General Understanding and Manufacturing Techniques of Carbon Fibers," Carbon Letters, vol. 9, no. 225, 2008.

[4] Y. Yu and R. Luo, "Oxidation behavior of carbon/carbon composites coated with a $\mathrm{Si}-\mathrm{SiO}_{\mathrm{x}} / \mathrm{BN}-\mathrm{B}_{2} \mathrm{O}_{3}-\mathrm{SiO}_{2}-\mathrm{Al}_{2} \mathrm{O}_{3}$ oxidation protection system at intermediate temperature," Vacuum, vol. 128, no. 9, 2016.

[5] S. J. Park, M. K. Seo and J. R. Lee, "Influence of Oxidation Inhibitor on Carbon-Carbon Composites: 6. Studies on Friction and Wear Properties of Carbon-Carbon Composites," Polym. Korea, vol. 25, no. 133, 2001.

[6] G. S. Kim, "Study on the development and application of advanced carbon composites," Ceramist, vol. 12, no. 91, 1997. 